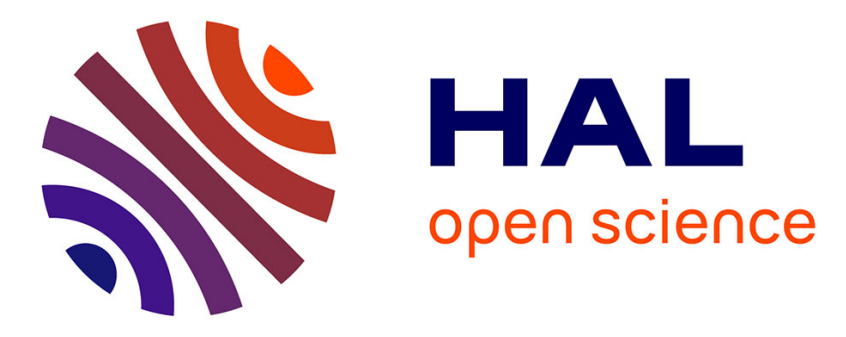

\title{
Hygrothermal characterization of a new bio-based construction material: Concrete reinforced with date palm fibers
}

\author{
Nawal Chennouf, Boudjemma Agoudjil, Abderrahim Boudenne, Karim
}

Benzarti, Fathi Bouras

\section{To cite this version:}

Nawal Chennouf, Boudjemma Agoudjil, Abderrahim Boudenne, Karim Benzarti, Fathi Bouras. Hygrothermal characterization of a new bio-based construction material: Concrete reinforced with date palm fibers. Construction and Building Materials, 2018, 192, pp.348-356. 10.1016/j.conbuildmat.2018.10.089 . hal-03088983

\section{HAL Id: hal-03088983 https://hal.science/hal-03088983}

Submitted on 27 Dec 2020

HAL is a multi-disciplinary open access archive for the deposit and dissemination of scientific research documents, whether they are published or not. The documents may come from teaching and research institutions in France or abroad, or from public or private research centers.
L'archive ouverte pluridisciplinaire HAL, est destinée au dépôt et à la diffusion de documents scientifiques de niveau recherche, publiés ou non, émanant des établissements d'enseignement et de recherche français ou étrangers, des laboratoires publics ou privés. 


\title{
Hygrothermal characterization of a new bio-based construction materials: concrete reinforced with date palm fibers
}

\author{
Nawal Chennouf ${ }^{1,2,3}$, Boudjemma Agoudjil ${ }^{3 *}$, Abderrahim Boudenne ${ }^{1^{*}}$, Karim Benzarti ${ }^{4}$ and \\ Fathi Bouras ${ }^{2}$ \\ ${ }^{1}$ Université Paris-Est Créteil, CERTES, 61 Av. du Général de Gaulle, \\ 94010 Créteil Cedex, France. \\ ${ }^{2}$ University Echahid Hamma Lakhdar El-Oued, PO Box 789 EL Oued, Algeria. \\ ${ }^{3}$ Université Batna 1/LPEA, 01 Rue Boukhlouf Med El Hadi 05000 Batna, Algeria. \\ ${ }^{4}$ Université Paris-Est, Laboratoire NAVIER, UMR8205, IFSTTAR, \\ F77447 Marne la Vallée, France.
}

\begin{abstract}
Hygrothermal behavior of a new building material, composed of cement, sand and date palm fibers was investigated in the present work. In a first part, the sorption-desorption isotherm behavior and the hysteresis effect was characterized under static conditions, revealing the high hydric capacity of this Date Palm Cement (DPC) mortar. In addition, the application of GAB model (Guggenheim- Anderson- de Boer) successfully described the experimental sorption isotherm curve. In a second step, the moisture buffer value and the effect of temperature on successive adsorption/desorption cycles were assessed under dynamical conditions. It was found that the sorption process is highly affected by temperature. Finally, this bio-based mortar was classified as hygroscopic and breathable material with excellent moisture buffering capacity.
\end{abstract}

Keywords:

Date palm fibers, concrete, moisture buffer value, effect of temperature, adsorptiondesorption curve 
1 Corresponding authors:

2 *Dr. AbderrahimBoudenne; email: boudenne@u-pec.fr; Université Paris-Est Créteil Val de 3 Marne/CERTES, 61 Av. du Général de Gaulle 94010 Créteil, France.

4 *Pr. Boudjemaa Agoudjil; email: b.agoudjil@yahoo.fr; Université Batna 1/LPEA, 01 Rue 5 Boukhlouf Med El Hadi 05000 Batna, Algérie. 


\section{$1 \quad$ Nomenclature}

2 Roman

3 A Exposed surface area $\left(\mathrm{m}^{2}\right)$

$4 \quad b_{m} \quad$ Moisture effusivity $\left(\mathrm{kg} / \mathrm{m}^{2} \mathrm{~Pa} \mathrm{~s}^{1 / 2}\right)$

$5 \quad \mathrm{C}_{\mathrm{Gj}} \quad$ Fitting parameter

$6 \quad \mathrm{~d}_{\mathrm{p}, 1 \%} \quad$ Penetration depth (m)

$7 \quad D_{w} \quad$ Moisture diffusivity

8 e Sample thickness (m)

$9 \mathrm{G}$ Rate of mass change $(\mathrm{kg} / \mathrm{s})$

$10 \mathrm{~g}$ Gravity acceleration $\left(9.81 \mathrm{~m}^{2} / \mathrm{s}\right)$

$11 \quad \mathrm{k}_{\mathrm{j}} \quad$ Fitting parameter

$12 \quad \mathrm{M}_{1} \quad$ Molar weight of water $(18 \mathrm{~g} / \mathrm{mol})$

13

$14 \mathrm{~m}$ mass $(\mathrm{kg})$

$15 \mathrm{~m}_{0} \quad$ dry weight $(\mathrm{kg})$

$16 \mathrm{~m}_{\mathrm{w}} \quad$ Wet weight $(\mathrm{kg})$

$17 \mathrm{n}_{\mathrm{j}} \quad$ Fitting parameter

$18 \mathrm{p}_{\mathrm{v}} \quad$ Vapor pressure $(\mathrm{Pa})$

$19 \mathrm{p}_{\mathrm{vs}} \quad$ Saturation vapor pressure $(\mathrm{Pa})$

$20 \mathrm{R}$ Ideal gas constant $(8.134 \mathrm{~J} / \mathrm{mol} \mathrm{K})$

21 RH Relative humidity (\%)

$22 \quad \mathrm{Sd}_{\mathrm{tot}} \quad$ Total vapor diffusion thickness (m)

$23 \mathrm{~T}$ Temperature $(\mathrm{K})$

$24 \mathrm{t} \quad$ temps (s)

$25 \quad t_{p} \quad$ Cycle period (24 hours)

26 W Water content $(\mathrm{kg} / \mathrm{kg})$

\section{Greek}

$\delta_{0} \quad$ Dry permeability $(\mathrm{kg} /(\mathrm{m} \mathrm{s} \mathrm{Pa}))$

$\delta^{*} \quad$ Fictitious permeability $(\mathrm{kg} /(\mathrm{m} \mathrm{s}$

$\mathrm{Pa})$ )

$\alpha \quad$ Fitting parameter

$\theta \quad$ Moisture capacity

\section{Subscripts}

ads Adsorption

des Desorption

$\mathrm{f} \quad$ free saturation

hys Hysteresis

Sat Saturation 


\section{Introduction}

Reduction of energy consumption and development of bio-economy are among the major concerns of sustainable development. In the field of building physics, many policy programs have been launched around the world so far [1], such as: the Sustainable Building Plan and the Law on Ecological and Energy Transition in France, the Zero Carbon Standard and the Climate Change Act in England, the Bio-preferred Program in the United States, the UAE Green Growth Strategy in the United Arab Emirates, etc...

These programs focus on the promotion of selected bio-based materials (wood, hemp, recycled textiles, cellulose wadding, straw, linen and date palm fibers) [2, 3], which provide organic and renewable solutions for building applications. The choice of these materials and the measure of their profitability are based on few criteria, such as availability, cost of treatment, etc...

Date palm wood has a strong potential as insulating building material, since it is a renewable and abundant material and its annual worldwide production is estimated over 1200000 tons of petioles, 410000 tons of leaves and 300000 tons of bunches [3].

Studies have shown that the renewable parts (petioles, leaves, bunches) of the date palm wood exhibit excellent insulating capacity [3,4]. These components can be used as reinforcement in several types of matrices, such as gypsum, polymer and concrete $[4,5,6,7,8]$, to form date palm reinforced composites. Usually, thermo-physical characterizations of such composites also demonstrate very good performances in terms of thermal insulation.

Furthermore, Benmansour et al. showed that introducing 15 weight $\%$ of date palm fibers in concrete provides a composite with good thermal and mechanical properties, which can be used as structural material in building components [4].

Nevertheless, little is known about hygric characteristics of these new Date Palm Cement (DPC) composites, as very few studies are available on the subject in the literature. Recently, Haba et al. explored the porous and hygroscopic structure of DPC and revealed their high moisture 
absorption and storage capacities [9]. Still, no data can be found regarding the moisture buffer performance and the moisture transfer of these materials under dynamic condition.

Both temperature and humidity of inhaled air has an impact on human perception of the indoor comfort level [10]. In order to limit fluctuations in internal humidity and temperature, the materials constituting the envelope of a building must have the ability to store and release moisture [11-14]. Such ability can be quantified through the determination of the Moisture Buffer Value (MBV) and the sorption-desorption capacity.

Several studies were performed on conventional [14] and bio-based [13, 15, 16] building materials. Collet et al. [13] have compared the behavior of three kinds of hemp concrete: a precast compacted hemp concrete, a sprayed hemp concrete and a molded hemp concrete with fibred hemp shiv . Their results revealed different hysteresis behaviors for the 3 materials, as well as a low sorption capacity for prefabricated hemp concrete. Such differences in the sorption/desorption process induced large variation of MBV for the 3 hemp concretes under study [13].

In the same context, Oumeziane et al. [15] proved that a single sorption curve (which is the usual method) is not able to describe the evolution of the water content of hemp concrete and leads to an overestimation of the actual water capacity. Thus, according to these authors [15, 17], it is necessary to introduce the phenomenon of hysteresis. Up to now, simulation tools rely on the sorption-desorption isotherm and on temperature dependency to predict humidity and temperature transfers in porous materials. Several experimental studies have been conducted to investigate the effects of both temperature and hysteresis on the evolution of the moisture content in bio-based concretes, and showed that the moisture content decreases when the temperature is raised. Nevertheless, the deviation between moisture contents determined at $10^{\circ} \mathrm{C}$ and $23{ }^{\circ} \mathrm{C}$ remains low at high relative humidity [17]. 
In the present work, it is proposed to complete previous studies dedicated to thermo-physical and mechanical characterizations of date palm cement composites [4] with a complementary investigation on the hygro-thermal behavior. This work has been initiated by Haba et al. [9].

In this paper, the moisture buffer performance of DPC composites is assessed according to the Nordtest protocol [18]. The goal is to evaluate the ability of DPC to dampen the indoor relative humidity while taking into account the influence of temperature. Since the usual approach based on the sorption curve and the water vapor permeability cannot provide good prediction of the hysteretic behavior [13], a new method is proposed, based on (i) the experimental characterization of adsorption-desorption isotherms, (ii) the numerical determination of intermediate sorption capacities, and (iii) a modeling of the hysteretic behavior using the phenomenological model of Mualem [19].

\section{Materials}

DPC samples were prepared according to the experimental protocol proposed by Benmansour et al. [4]. Vegetal components were based on petiole clusters and rachis part of date palm trees from Bentious oasis in Mekhadma (province of Biskra-Algeria) [3]. This raw material was rinsed then let dried under natural conditions and was then subjected to two levels of grinding (crushing followed by crude grinding) in order to obtain fibers of maximum length $5 \mathrm{~mm}$ and mean diameter $3 \mathrm{~mm}[3]$.

In the present work, a single formulation was chosen for the composition of DPC composites (Table 1), consisting of 15 wt.\% date palm fibers, 62 wt.\% cement (CEM II/B-LL32.5R CE NF) and $23 \mathrm{wt} \%$ sand with 0 to $4 \mathrm{~mm}$ of mean particle size. This formulation has shown interesting thermo-physical and mechanical properties according to RILEM specifications for insulating lightweight concrete used in building applications [4].

DPC samples were prepared by mixing date palm fibers, cement and sand in a mixer ( $40 \mathrm{rd} / \mathrm{min})$ for 5 minutes. Dry mixing was first carried out to homogenize the components, and tap water 
$1 \quad(7.7 \mathrm{pH})$ was then added gradually. Afterwards, the mixture was poured into the molds; samples

2 were demolded one week later and then dried for two months under standard laboratory 3 conditions $\left(\mathrm{RH} \approx 45 \%\right.$ and $\left.\mathrm{T} \approx 21^{\circ} \mathrm{C}\right)$. An example of the obtained samples for several sizes is 4 presented in Figure 1.

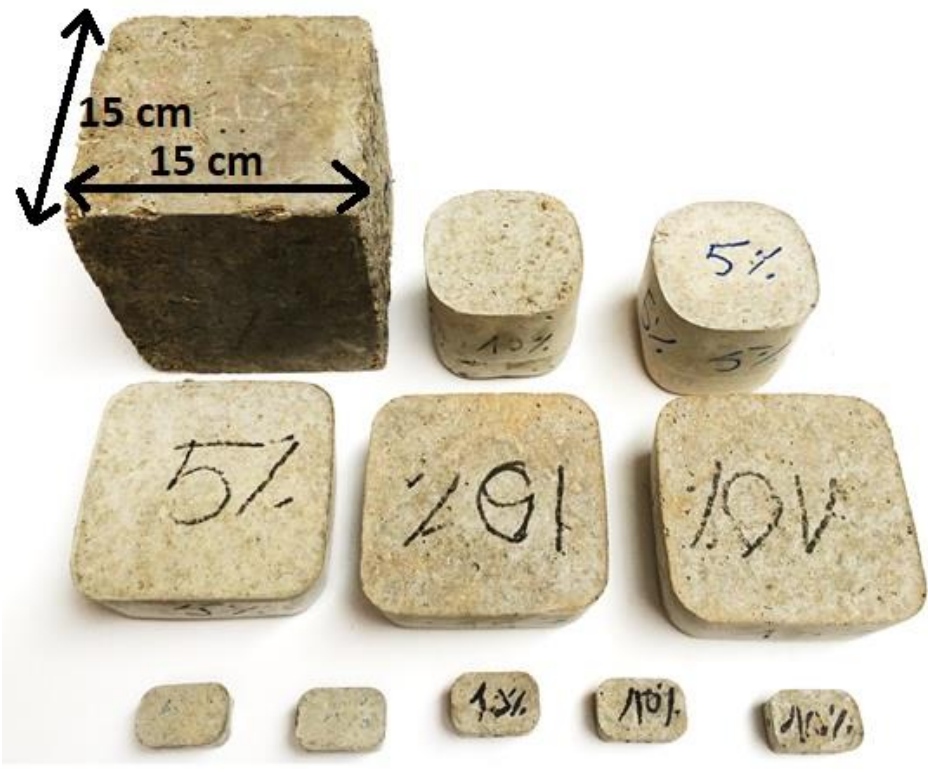

Figure 1: DPC samples testing.

Table 1: Composition of DPC specimens.

\begin{tabular}{lcc}
\hline Components & $\begin{array}{c}\text { Weight ratio } \\
(\boldsymbol{\%})\end{array}$ & $\begin{array}{c}\text { Weight content per } \\
\text { batch }(\mathbf{k g})\end{array}$ \\
\hline Cement & 62 & 11.40 \\
Sand & 23 & 4.21 \\
Date palm fibers & 15 & 2.75 \\
Water/cement ratio & 0.68 & 0.68 \\
\hline
\end{tabular}

\section{Methods}

\subsection{Determination of the Moisture Buffer Value}

The practical Moisture Buffer Value (MBV) indicates the amount of water transported in or out of a hygroscopic material per open surface area, during a defined time, when the material is 
1 subjected to variations in relative humidity of the surrounding air. The unit of $\mathrm{MBV}$ is

$2\left[\mathrm{~kg} /\left(\mathrm{m}^{2} \% \mathrm{RH}\right)\right][18]$. The initial mass of samples used for MBV measurement is determined

3 when the equilibrium is reached i.e. $50 \% \mathrm{RH}$ and $23^{\circ} \mathrm{C}$.

4 To assess the ability of DPC composites to buffer (store and release) moisture of the

5 surrounding air, the method defined by the Nordtest project [20] was used. This protocol

6 consists in exposing the sample to constant temperature with a cyclic variation of the relative

7 humidity $(\mathrm{RH})$ between high $(75 \% \mathrm{RH})$ and low $(33 \% \mathrm{RH})$ levels for periods of 8 and 16 hours

8 respectively. This protocol was applied at two different temperatures $\left(23^{\circ} \mathrm{C}\right.$ and $\left.10^{\circ} \mathrm{C}\right)$ in order

9 to evaluate the effect of temperature on the moisture buffering performance of DPC. These two

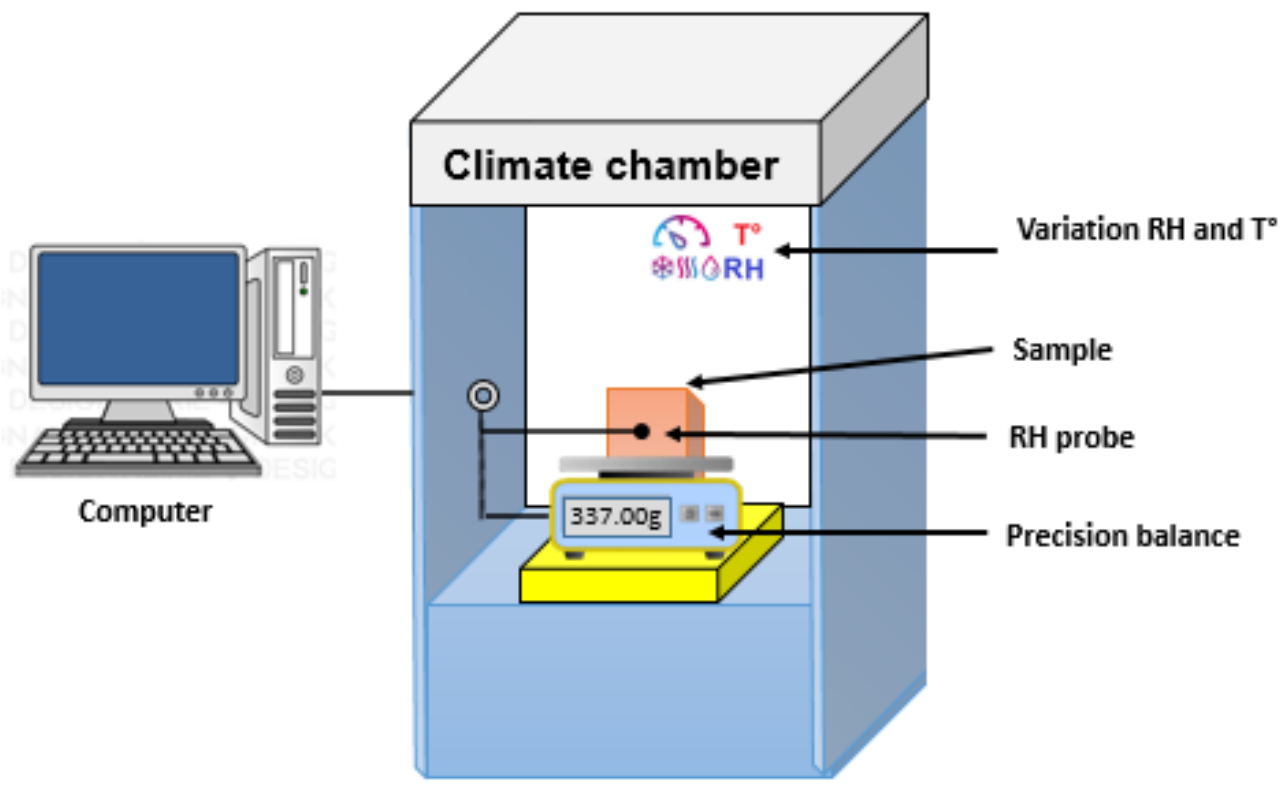

11

Figure 2: Experimental device used to evaluate moisture buffering of DPC.

For MBV measurements, samples with an average volume of $\left(95 \times 65 \times 60 \mathrm{~mm}^{3}\right)$ were sealed on five sides with aluminum sheet, in order to ensure a $1 \mathrm{D}$ transfer across the open surface at the upper side of the specimen (see Figure 2). The sample was then placed on a Sartorius precision 
1 balance with readability of $0.001 \mathrm{~g}$, and this entire setup was installed in a climatic chamber

2 (Memmert HPP 750 with setting accuracy temperature $0.1{ }^{\circ} \mathrm{C}$ and accuracy humidity $0.5 \% \mathrm{RH}$

3 ) conditioned at $23^{\circ} \mathrm{C}$ and $50 \% \mathrm{RH}$, until the weight variation of the sample became less than

$4 \quad 0.1 \%$ per $24 \mathrm{~h}$. Once this specification was achieved, the cyclic variation of relative humidity 5 was launched (cycles of 8 hours at $75 \% \mathrm{RH}$ followed by 16 hours at $33 \% \mathrm{RH}$ ) and the MBV 6 test started.

7 During $\mathrm{RH}$ cycling, temperature and relative humidity of the sample were monitored at a depth 8 of 35mm, using high-precision both temperature and relative humidity sensors (DKRF400

9 Series: operate at a temperature range of $-40^{\circ} \mathrm{C}$ to $+80^{\circ} \mathrm{C}$ with accuracy of $0.3^{\circ} \mathrm{C}$ and operate within a range of $0 \ldots 100 \% \mathrm{RH}$ and offers an accuracy of $1.8 \%$ ). The sample weight was automatically recorded every 5 seconds via computer piloted acquisition. This procedure ended when the change in weight $\Delta \mathrm{m}$ was less than $5 \%$ between three consecutive cycles [18] and the MBV value was then calculated at the steady state according to Equation 1

$$
M B V=\frac{\Delta m}{A\left(R H_{\text {high }}-R H_{\text {low }}\right)}
$$

With MBV: the moisture buffer value $\left[\mathrm{kg} /\left(\mathrm{m}^{2} \% \mathrm{RH}\right)\right], \Delta \mathrm{m}$ : the moisture uptake/release during the last cycle $[\mathrm{kg}], \mathrm{A}$ : the mean open surface area of the sample $\left[\mathrm{m}^{2}\right]$ (the mean of three measurement of length $\times$ the mean of three measurement of width), $\mathrm{RH}_{\text {high }}$ : high relative humidity level and $\mathrm{RH}_{\text {low: }}$ low relative humidity level.

The penetration depth corresponds to the depth where the variation of the moisture content becomes lower than $1 \%$ of the amplitude at the surface of the sample; it is calculated using Equation 2.

$$
D_{w}=\frac{\delta_{0} \cdot p_{v s}}{\frac{\partial w}{\partial R H}}
$$


$3 \frac{\partial w}{\partial R H}$ is the specific hygric capacity $\left[\mathrm{kg} / \mathrm{m}^{3}\right], \delta_{v s}$ is the water vapor permeability $[\mathrm{kg} /(\mathrm{msPa})]$,

4 This step was followed by the determination of the ideal MBV. This buffer property represents 5 a dynamic characteristic calculated using the moisture effusivity $b_{m}$ which is determined under 6 steady state conditions:

7

$$
M B V_{\text {ideal }} \approx 0.00568 \cdot p_{v s} \cdot b_{m} \cdot \sqrt{t_{p}}
$$

$b_{m}$ describes the ability of a material to absorb or release moisture $\left[\mathrm{kg} /\left(\mathrm{m}^{2} \mathrm{~Pa} \mathrm{~s} / 2\right)\right]$, and can be obtained using Equation 5.

$$
b_{m}=\sqrt{\frac{\delta_{0} \cdot \frac{\partial w}{\partial R H}}{p_{v s}}}
$$

\subsection{Evaluation of the water vapor permeability}

The water vapor permeability is an important material property which characterizes the material ability to transfer the moisture (diffusion, effusion and liquid transfer) when there is a vapor pressure differential. The measurement of the water vapor permeability was determined according the cup method described in EN ISO 12572 [21], under isothermal condition at $23^{\circ} \mathrm{C}$.

The samples $\left(61 \mathrm{~cm}^{2}\right.$ of mean exposed surface and $2.5 \mathrm{~cm}$ of thickness) were conditioned at $23^{\circ} \mathrm{C}$ and $50 \% \mathrm{RH}$ until weight stabilization.

To achieve the one directional moisture flow, the specimens were embedded on the top of the cups that contained specific compounds for moisture control (solution of potassium nitrate in the wet cup and silica gel in the dry cup). This allowed to keep the relative humidity of the air layer in the cup at $95 \%$ for the wet state and about $3 \%$ for the dry state, and so were the RH levels at the bottom surfaces of the embedded DPC specimens as well. In each cup, the height 
of the air layer between the specimen and the saline solution/silica gel was about $2.5 \mathrm{~cm}$, as shown in Figure 3. The two cups were both placed in an environment at $23^{\circ} \mathrm{C}$ and $50 \% \mathrm{RH}$.

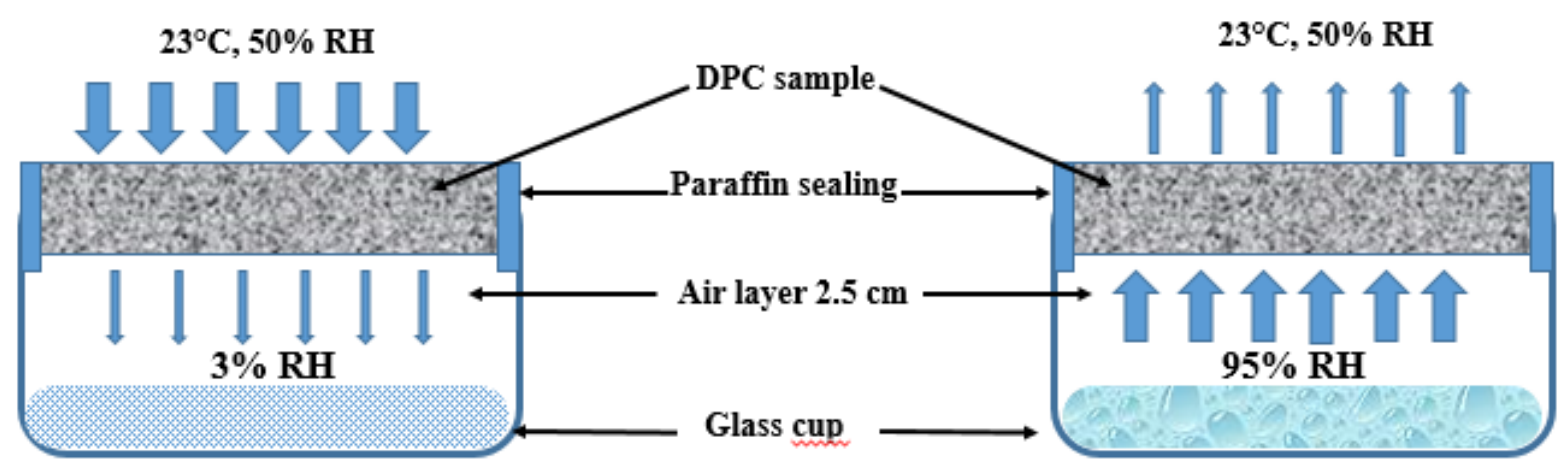

Figure3: Operating diagram of the experimental setup for water vapor permeability measurement.

The weight of the device was measured each day until obtaining a constant mass within $\pm 5 \%$ of the mean value of the specimen. The rate of mass change " $G$ " created by the difference of water vapor pressures was calculated as follows:

$$
G=\frac{\Delta m}{\Delta t}
$$

Then the water vapor permeability $\delta\left(\delta_{0}\right.$ : dry permeability, $\delta^{*}$ : fictitious permeability)

$[\mathrm{kg} /(\mathrm{m} \mathrm{sPa})]$ was deduced from Equation 7.

$$
\delta=\frac{G \cdot e}{\Delta p_{v} A}
$$

Considering that there is an ideal mixing of the humid air inside the cup, the fictitious and dry vapor resistance factor $(\mu)$ was corrected as follow:

$$
p_{v}=R H \exp (23.5771-(4042.9 /(T-37.58)))
$$




$$
\mathcal{B} d_{t o}\left(\overline{s t} \delta_{t o a} A A p\right), / R G
$$

2 With $S d_{t o t}$ : total vapor diffusion thickness in m, $e_{a}$ : thickness of air layer between the

3 specimen and the saline solution inside the cup in [m].

$4 \quad \delta_{a}$ is the water vapor permeability of air and can be expressed as follows:

5

$$
\delta_{a}=2.31 .10^{-5} \frac{M_{l}}{R T}\left(\frac{T}{273.15}\right)^{1.81}
$$

\subsection{Assessment of the sorption-desorption behavior}

The hygroscopic curve describes the equilibrium between the water content of the studied material and relative humidity of surrounding air [12]. This characteristic can be measured according to continuous or discontinuous methods [13]. In the present work, the discontinuous method described in ISO12571 standard was used [22]. According to this method, samples were dried for $120 \mathrm{~h}$ in an oven at $62{ }^{\circ} \mathrm{C}$ in order to extract all moisture or water. Dimensions of samples $\left(30 \times 20 \times 25 \mathrm{~mm}^{3}\right)$ were chosen to embed the representative volume of the DPC material.

To determine the adsorption isotherm, the samples were successively exposed to increasing humidity levels: $10 \%, 30 \%, 50 \%, 75 \%$, and then finally $90 \% \mathrm{RH}$, while keeping the temperature constant in the climatic chamber. For the desorption isotherm, the process is carried out in inverse order.

For each RH level, the samples were periodically weighed until they reached a constant mass (i.e., the mass change between three consecutive weighing, made at least $24 \mathrm{~h}$ apart from each other, was less than $0.1 \%$ of the total mass).

The water content was calculated from the following Equation:

$$
w=\frac{m_{w}-m_{0}}{m_{0}}
$$




\subsection{Theory}

10

\subsubsection{Modeling of the Sorption-desorption behavior}

Several models have been developed in the literature to describe the relationship between relative humidity of air and the moisture content in porous materials $[13,15,16]$. Among existing models, Langmuir [23], VG (Van Genuchten) [24], GAB (Guggenheim-Anderson-de Boer) and BET models can be cited $[25,26]$. In the present paper, VG and GAB models were implemented, since they are often used for describing hygroscopic behavior of materials over the entire relative humidity range.

In VG model, the water content $w$ is described by Equation13 [24]:

$$
w=w_{s a t}\left(1+\left(\frac{\alpha R T}{M_{l} g} \cdot \ln (R H)\right)^{n_{j}}\right)^{-\left(1-\frac{1}{n_{j}}\right)} \quad j=a d s \text { or des }
$$

In GAB model, which is based on the physical sorption mechanism, w varies according to Equation $14[25]$ :

$$
w=\frac{w_{m j} C_{G j} K_{j} R H}{\left(1-K_{j} R H\right)\left(1-K_{j} R H+C_{G j} K_{j} R H\right)} \quad j=\text { ads or des }
$$

Where $K_{j}$ value was determined from the best linearization plot of $w(G A B)$ versus $R H$. The two other constants, $w_{m j}$ and $C_{G j}$, were then determined from two linear regression coefficients $(j$ represents the adsorption or desorption curve like in the VG model).

\subsubsection{Hysteresis model}

For a given relative humidity $\mathrm{RH}$, a porous material tends toward different equilibrium moisture contents if it is in a phase of adsorption (increasing $\mathrm{RH}$ ) or desorption (decreasing $\mathrm{RH}$ ); it is the hysteretic behavior. In this paper, Mualem's model was used to evaluate the sorption capacity 
1 during intermediate adsorption and desorption phases, based on the main adsorption-desorption

2 values $[17,19]$ :

$$
\begin{aligned}
& \theta_{a d s, h y s}=\frac{w_{f}-w_{d e s}\left(R H_{i}\right)}{w_{f}-w_{a d}} \theta_{a d s} \\
& \theta_{d e s, h y s}=\frac{w_{f}-w_{d e s}}{w_{f-} w_{a d s}} \theta_{a d}-\left(w_{a d s}\left(R H_{j}\right)-w_{a d s}\right) \times \frac{\left(w_{f}-w_{d e s}\right) \theta_{a d s}-\left(w_{f}-w_{a d s}\right) \theta_{d e s}^{4}}{\left(w_{f}-w_{a d s}\right)}
\end{aligned}
$$

$6 \quad$ " $i$ " and " $j "$ are the minimal and maximal levels reached by the relative humidity during an

7 adsorption-desorption cycle.

\section{$8 \quad 4 \quad$ Results and discussion}

9

10

\subsection{Analysis of the sorption and desorption isotherms at $23^{\circ} \mathrm{C}$}

Figure 4.adisplays the experimental adsorption isotherm at $23^{\circ} \mathrm{C}$ and the fitting curves using VG and GAB models, for the DPC composite. The graph provides a type II curve, according to the IUPAC classification of adsorption isotherms [27], which corresponds to non-porous materials. Identified GAB and VG constants are given in Table 2.

The fitted adsorption curve using GAB model shows globally a good agreement with experimental data over the entire humidity range, while the VG model provides accurate values in the capillary condensation range only, and deviates from experimental values at low $\mathrm{RH}$ levels.

Table 2: Fitting parameters of $G A B$ and VG models for adsorption and desorption isotherms at $23^{\circ} \mathrm{C}$

\begin{tabular}{lcccc}
\hline Model & \multicolumn{2}{c}{ Adsorption } & \multicolumn{2}{c}{ Desorption } \\
\cline { 2 - 5 } & Parameters & Values & Parameters & Values \\
\hline GAB model & $K_{\text {ads }}$ & 0.038 & $K_{\text {des }}$ & 0.416 \\
& $\mathrm{C}_{\text {Gads }}$ & 0.733 & $\mathrm{C}_{\text {Gdes }}$ & 91.285 \\
& $\mathrm{~W}_{\mathrm{m} \text { ads }}$ & 0.003 & $\mathrm{~W}_{\mathrm{m} \text { des }}$ & $8.4 \times 10^{6}$
\end{tabular}


2 For this reason, the GAB model was also used to fit the desorption curve of the DPC composite.

3 Figure 4.b shows on the same graph the adsorption and desorption curves fitted by the GAB model, together with the experimental data. Parameters of the GAB model for desorption are also listed in Table 2.

Regarding the kinetics of adsorption, DPC exhibited very similar characteristics compared to other very hygroscopic materials used in building applications, such as hemp or flax concrete $[11,12,16]$. In the domain of low water activity (RH between 10 and 50\%), the moisture content increased very quickly up to the equilibrium level (steady state reached after 10 days). This fast kinetics is due to the formation of water monolayer or to water strongly bonded to polar groups within the cell wall of date palm fibers (non-freezing water) at the sites of the most accessible internal surfaces and amorphous regions. Differently, in the domain of high relative humidity values (70-90\%), the moisture content increased very slowly up to a maximum water uptake of $0.18[\mathrm{~kg} / \mathrm{kg}]$ and the steady stat was reached after more than two months. This slow kinetic process is associated to the sorption of water into the inner surfaces and crystalline regions and results from the formation of water multi-layers or layers weakly bonded to the substrate. Such a behavior reflects the high hygroscopic character of DPC. The difference in moisture uptake behavior at different water activity levels may be due to the fibrous structure of the material and its porosity. It can be concluded that the use of this DPC material can be advantageous in terms of moisture control and for minimizing interstitial condensation when exposed to high $\mathrm{RH}$ environments. 


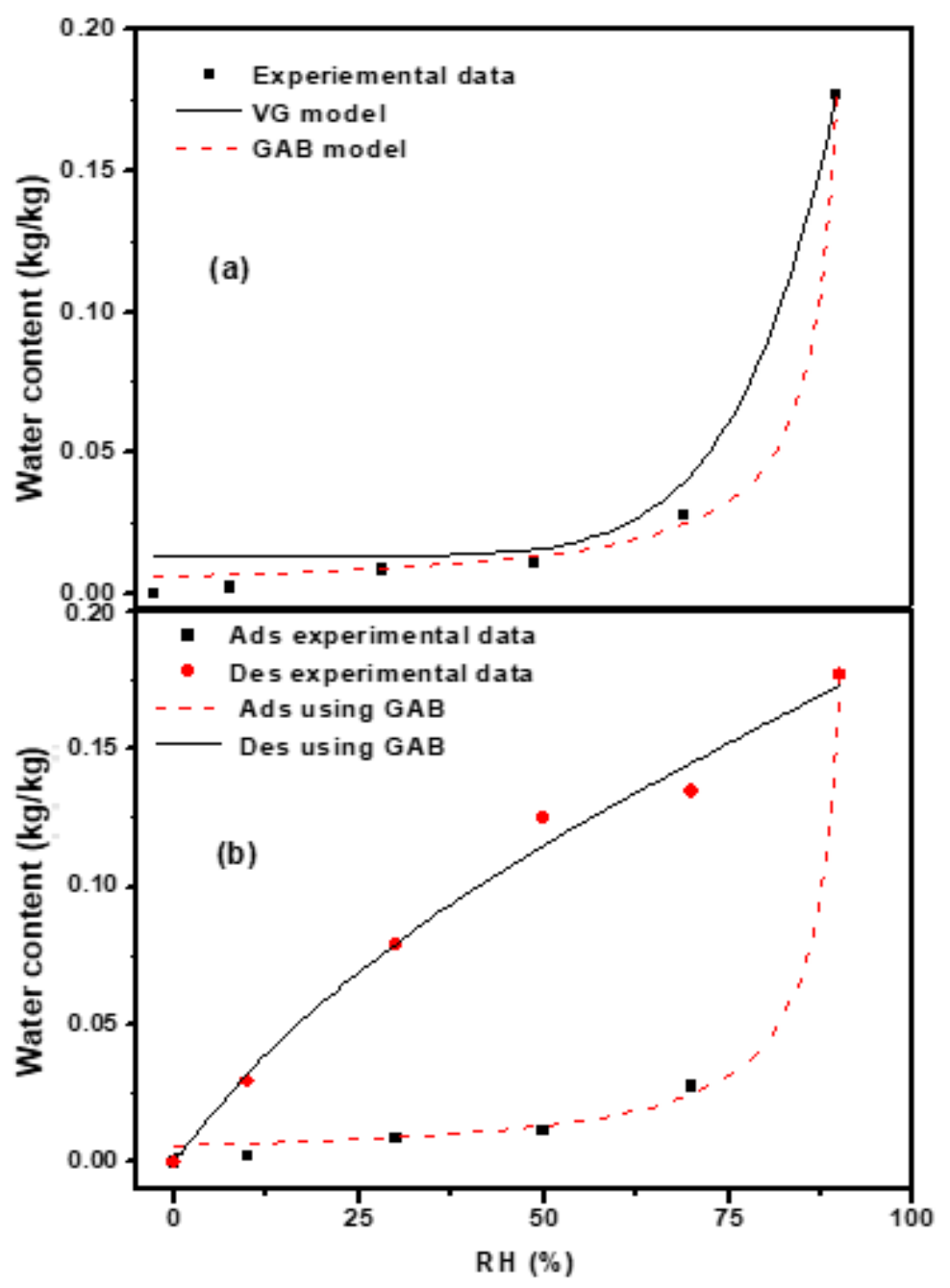

Figure 4: (a) Adsorption isotherm at $23^{\circ} \mathrm{C}$ : experimental data and theoretical curves by GAB and VG models, (b) Comparison of experimental data with Adsorption/desorption curves fitted by GAB model.

5 Furthermore, a large hysteresis is observed between the adsorption and the desorption curves, especially in the medium RH range (around 50\% RH). According to Chen et al. [28], deviations 7 between the adsorption and desorption curves originate from changes in the contact angle

8 between the adsorbed water and the internal surface of the material. During the desorption 9 cycle, the water coating present in the internal micro capillaries of the cell wall is in contact with an already fully wet surface, whereas during adsorption the formed water film is in contact with a non-wetted surface. 


\subsection{Hysteretic effect}

The absolute hysteresis obtained by subtracting the adsorption from desorption isotherm loop for the DPC material is presented in Figure 4. As previously mentioned in section 4.1, two distinct do mains can be observed, respectively characterized by fast and slow sorption kinetics. Indeed, the DPC exhibits a hysteresis phenomenon which is a common feature for bio-based materials, although significant differences can be observed among this type of materials. According to the IUPAC committee [27], the present hysteresis is classified as $\mathrm{H} 2$ type and is characteristic of materials with slit-like pores for which corresponds to the type II of sorption curve.

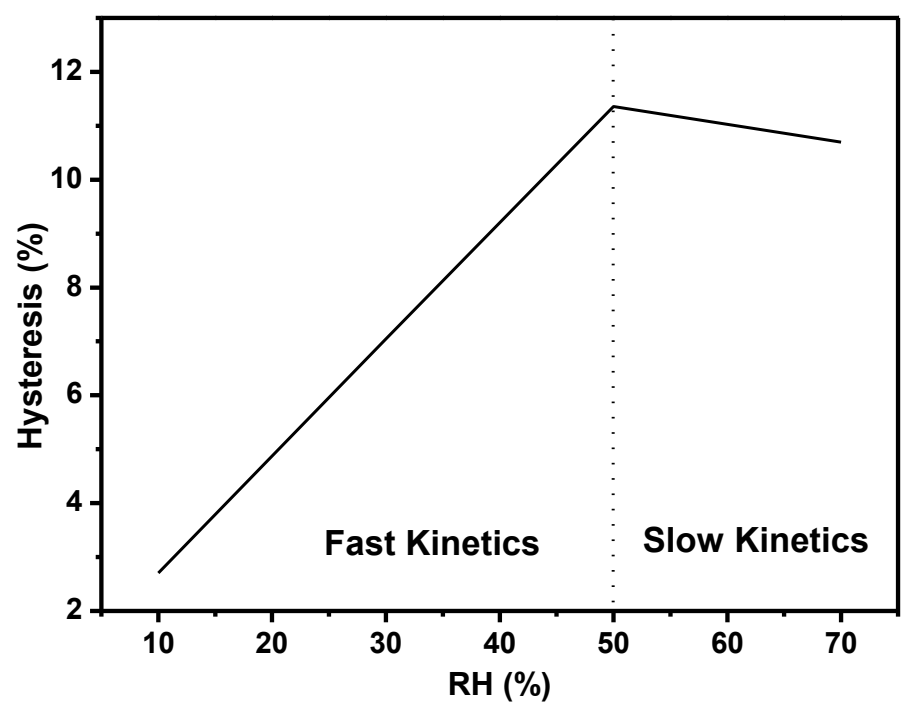

Figure 5: Hysteresis versus relative humidity for the main sorption cycle of the DPC specimen.

As can be seen in Figure 5, the increase of hysteresis obtained from experimental data is limited by the slow process at high humidity values (slow kinetic). This is probably due to the fact that the fast sorption process is correlated to the diffusion of water molecules in the cell wall, whereas the slow kinetics relates to relaxation processes associated to cell wall expansion.

According to Siau et al. [29], hysteresis can be explained by an incomplete rehydration of sorption sites during a subsequent adsorption cycle, and by the effect of compressive stresses 
1 during swelling as well. It is admitted in the literature, that the sorption hysteresis reduces the

2 specific hygric capacity $\left(\frac{\partial w}{\partial R H}\right)$ which relates to the derivative of sorption curve.

3 The main curves of adsorption (noted main ads) and desorption (noted main des) isotherms can

4 be considered as physical limits to changes in moisture content. Indeed, the evolution of the

5 water content under usual service conditions can be represented by the intermediate curve.

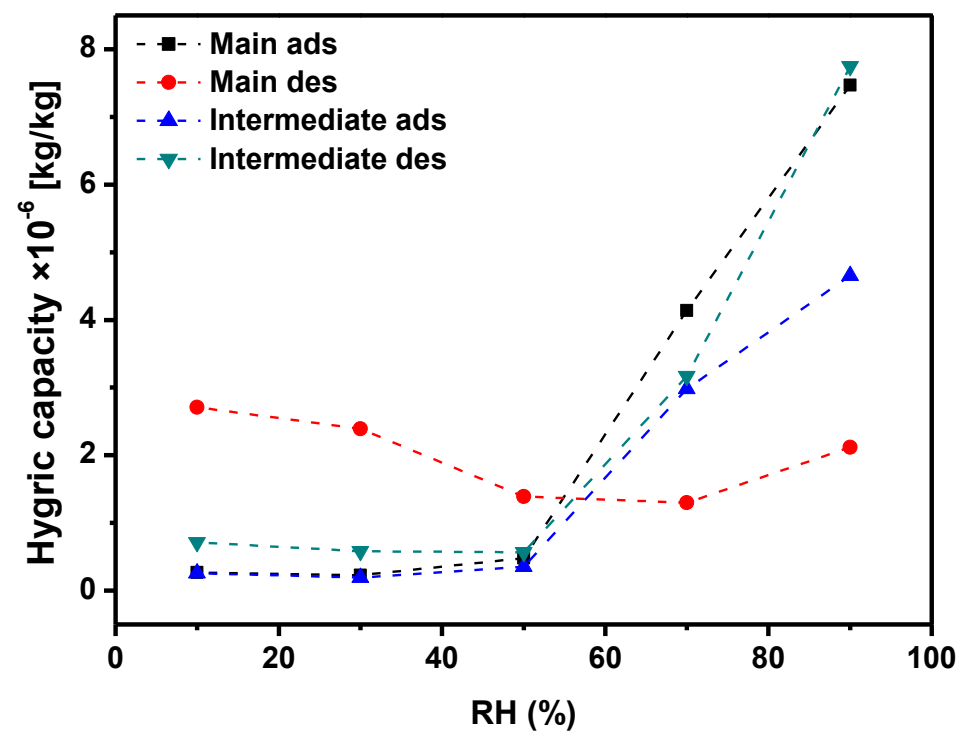

7

Figure 6: Hygric capacity of the DPC material.

The specific hygric capacity of intermediate adsorption and desorption curves(noted "intermediate ads" and "intermediate des") were obtained from the experimental main adsorption-desorption curves (Cf. Figure 4.b) using the Mualem's model (Equation 15) [19] are presented in Figure 6. We notice that until $60 \% \mathrm{RH}$, the hygric capacity curve of the intermediate desorption phase is little bit greater than the intermediate adsorption phase. At higher RH levels, this difference increases until to reaches about 0.075 in the condensation domain. This latter trend relates to the fact that water content obtained experimentally at $\mathrm{RH}=90 \%$ both on the main adsorption and desorption isotherms is the same (Cf. Figure 4.b). 
1 The intersection of the main curves corresponds to the decrease of the specific hygric capacity

2 resulted from the hysteresis of the slow kinetic section (Cf. Figure 5).

3 The intermediate desorption scanning curve shows a smaller moisture capacity than the main

4 desorption curve: for a given interval relative humidity, the variation in moisture content along

5 the adsorption scanning curve is smaller. This observation was also reported by Zhang et al.

6 [30] with regard to the moisture capacities of Klinki pine.

7 From this section, it can be concluded that DPC mortar can be advantageously used for building

8 applications in dry climate conditions, as it enables a regulation of interior humidity by

9 gradually restituting the adsorbed water over time.

\subsection{Water vapor permeability}

Table 3: $\mu$ and $\delta$ of DPC mortar.

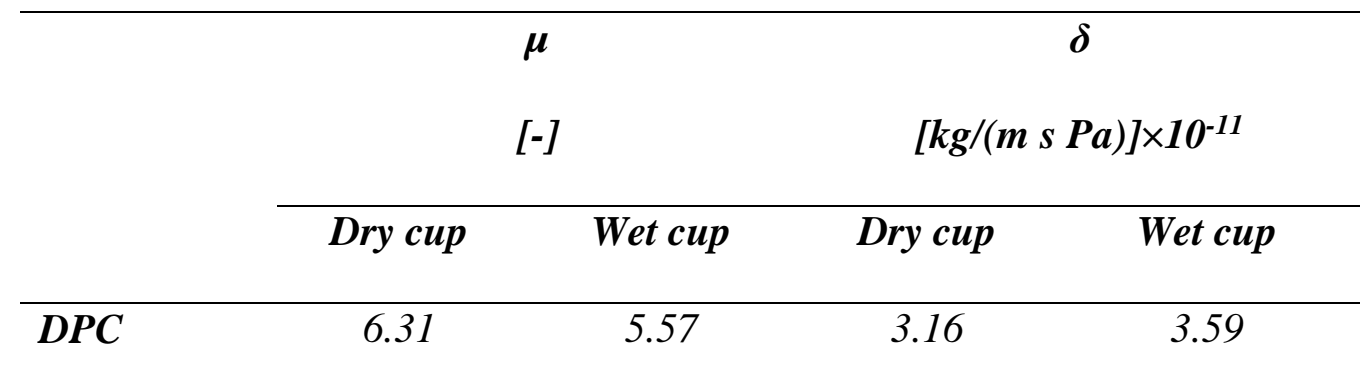




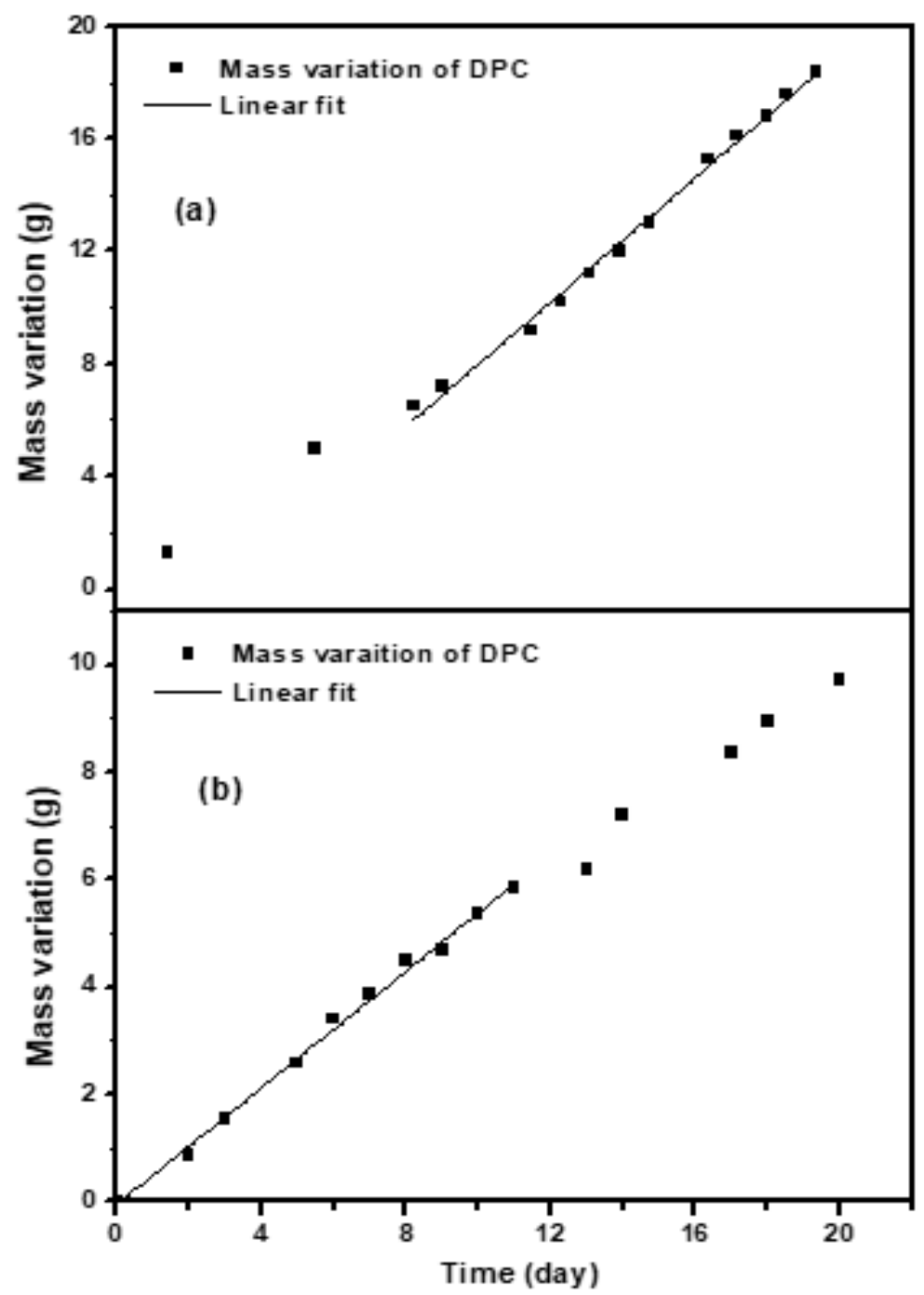

Figure 7: Mass variation kinetics during permeability measurements (a: wet cup, b: dry cup)

3

4 DPC material shows a slight increase in water vapor permeability from $3.16 \times 10^{-11}$ to $3.59 \times 10^{-11}$

$5 \quad[\mathrm{~kg} /(\mathrm{m} \mathrm{s} \mathrm{Pa})]$ when comparing dry and wet environments, respectively. This increase is due to

6 the enhancement of macroscopic moisture transport in water filled pore induced by capillary

7 condensation process.

8 Thus, for hysteretic material like DPC, the water vapor permeability is found to depend on the

9 moisture content. It can be also observed that the dry vapor diffusion resistance factor $(\boldsymbol{\mu})$ is 10 higher than the fictitious vapor diffusion resistance factor. As reported by Latif et al. [16], this 
1 is expected since vapor permeability is moisture dependent and the value of vapor permeability

2 rises with the increase of moisture content for insulation materials.

3

\section{$4 \quad 4.3 \quad$ Moisture buffer value}

5

6

7

8

9

\subsubsection{Classification of the MBV value for DPC mortar}

Figure 8 compares the moisture buffer value obtained for the DPC composite to that of several other bio-based materials. Before commenting the results, it is important to note that many factors (nature of the vegetal fillers, concentration, nature and formulation of the matrix, manufacturing process,...) may affect the behavior of bio-composite materials and consequently, comparing materials from different studies must be made with caution. Nevertheless, we took the initiative to make such a comparison between several materials of interest for construction applications in Figure 8.

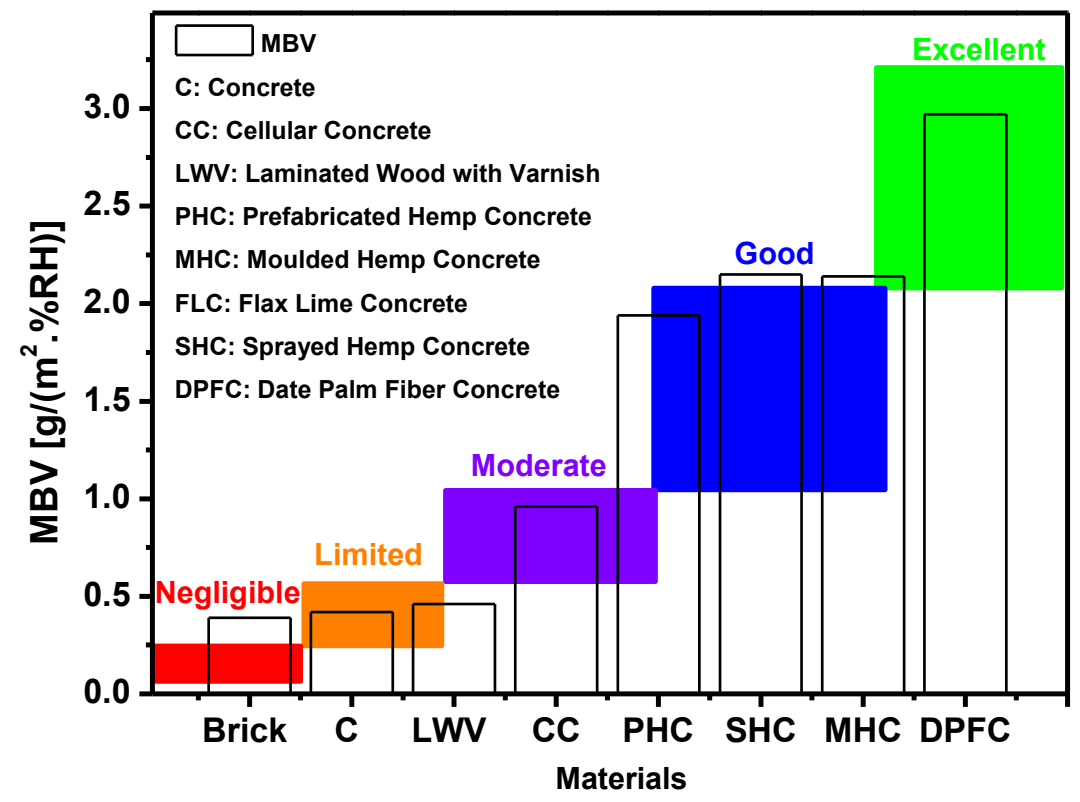

13

Figure 8: Comparison of the moisture buffer value (MBV) of DPC mortar with that of several 
1 It can be seen that the highest MBV value was achieved for the DPC composite

$2\left[2.97 \mathrm{~g} /\left(\mathrm{m}^{2} \% \mathrm{RH}\right)\right]$ followed by the other bio-sourced materials documented in the literature,

3 whereas traditional building materials such as concrete and brick showed the lowest MBV

4 values.

5 In terms of adsorption isotherm, the moisture diffusivity of DPC, obtained from Equation 3, is

$62.2 \times 10^{-9} \mathrm{~m}^{2} \mathrm{~s}^{-1}$ linked to their high porosity and hygroscopicity [33]. Such a high value is in

7 agreement with the excellent MBV value determined previously.

8 Moon et al. [31] and also Palumbo et al. [32], showed that materials with high MBV values

9 reduce condensation problems of the indoor air.

Thus, it can be concluded that DPC mortar exhibits excellent moisture buffer capacity and are classified as an excellent regulator of humidity according to the Nordtest classification.

\subsubsection{Effect of temperature on $M B V$}

In general, hygric transport properties are more sensitive to temperature changes than hygric storage properties [33]. The effect of temperature on adsorption-desorption phenomena depends on the type of material under study.

Table 4: Weight uptakes and releases during MBV tests at 10 and $23^{\circ} \mathrm{C}$

\begin{tabular}{lcc}
\cline { 2 - 3 } & $\mathbf{T}=\mathbf{2 3}^{\circ} \mathbf{C}$ & $\mathbf{T}=\mathbf{1 0}^{\circ} \mathbf{C}$ \\
\hline Av $\Delta \mathrm{m}_{\text {sor }}[\mathrm{g}]$ & 0.787 & 0.546 \\
Av $\Delta \mathrm{m}_{\text {des }}[\mathrm{g}]$ & 0.630 & 0.445 \\
\hline
\end{tabular}

Table 4 shows the average of weight uptake $\left(\operatorname{Av} \Delta m_{\text {sor }}\right)$ and the average weight release $\left(\operatorname{Av} \Delta \mathrm{m}_{\text {des }}\right.$ ) for the DPC sample during MBV tests conducted at $10^{\circ} \mathrm{C}$ and $23^{\circ} \mathrm{C}$. The amounts of weight uptake and release present a limited difference under isothermal conditions, but are dissimilar in the case of non-isothermal conditions. 
1 Variations of mass uptake and release under MBV test condition can also be represented by

2 plotting the change in moisture contents at high humidity $(\mathrm{RH}=75 \%)$ and at low humidity $(\mathrm{RH}$

$3=33 \%$ ) as a function of the number of successive cycles and for the two selected temperatures,

$4 \quad$ as shown in Figure 9.

5 One can notice from Figure 9 that temperature has a tremendous impact on the successive

6 sorption-desorption cycles.

7 The decrease in temperature leads to an increase in moisture content in adsorption phase at $75 \%$

$8 \mathrm{RH}$. This is generally explained by the increase of the number of adsorbed layers induced by

9 the decrease of the iso-steric heat of sorption (heat exchange in sorption phenomena under nonisothermal conditions) [35-36]. The moisture content at $10^{\circ} \mathrm{C}$ marks a significant hysteresis 11 phenomenon compared to the corresponding value at $23^{\circ} \mathrm{C}$ after the fourth cycle in adsorption 12 phase. This result can be explained by the reduction of additional moisture traced by the inkbottle effect due to the thermodynamic instability [37]. The inkbottle effect describes the hysteresis phenomenon type $\mathrm{H} 2$ [38].

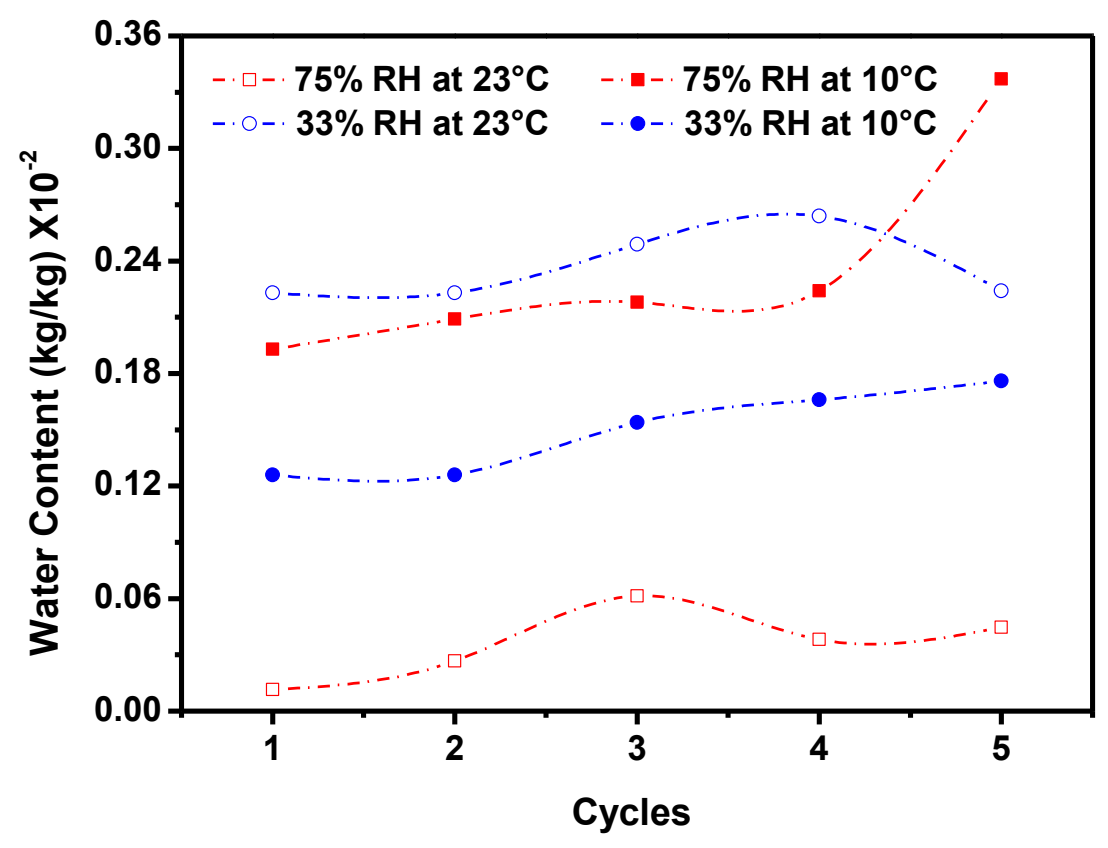

Figure 9: Temperature effect on sorption and desorption behavior of the DPC composite. 
1 In the desorption phase (at 33\% RH), the moisture content becomes lower with the decrease in

2 temperature, since this latter amortizes the transport phenomena $[34,36]$. The test lasted ten

3 days at $10^{\circ} \mathrm{C}$ and the cold induced the collapse of the pore structure and the evolution of water

4 properties, in contrast to the phenomenon of adsorption which is an exothermic phenomenon.

5 Figure 10 displays the kinetics of mass changes for the DPC material during the MBV tests at $6 \quad 10$ and $23^{\circ} \mathrm{C}$. Curves show similar features at these two temperatures. The steady state is 7 reached from the third cycle, and the average $\Delta \mathrm{m}$ between sorption and desorption becomes 8 less than $5 \%$ between the fifth cycle and the second one (i.e., 3 consecutive cycles).

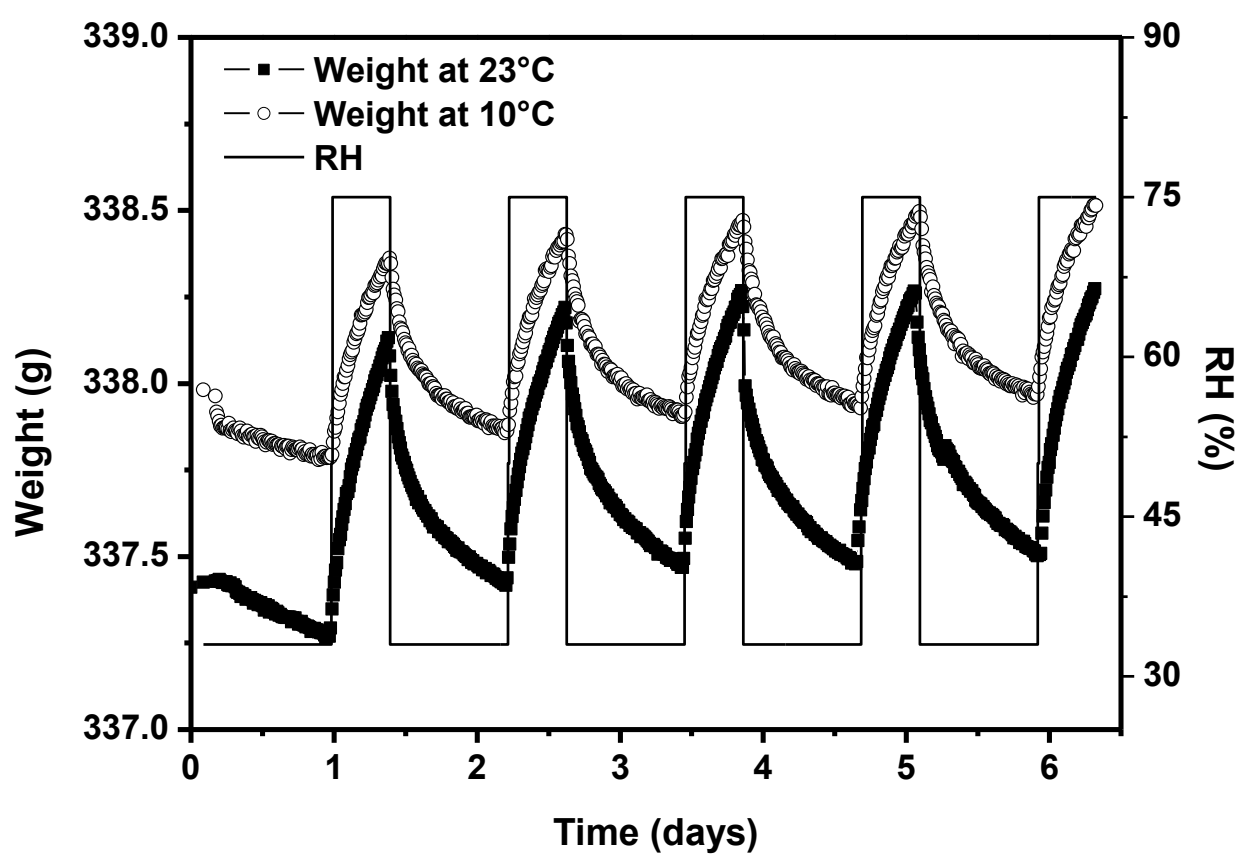

Table 5 reports MBV values determined at the two considered temperatures, i.e. 23 and $10^{\circ} \mathrm{C}$. It is found that the MBV values decrease as the temperature is lowered. For instance, MBVaverage decreases from $2.97\left[\mathrm{~g} /\left(\mathrm{m}^{2} \% \mathrm{RH}\right)\right]$ to $2.00\left[\mathrm{~g} /\left(\mathrm{m}^{2} \% \mathrm{RH}\right)\right]$, which represents a variation of $33 \%$. The similar trend is observed both for adsorption and desorption phases (MBV- 
1 adsorption and MBV-desorption). The same observations have been reported by Mazhoud et

2 al. [34] for two hemp-lime plasters, but the variation was about $59 \%$ and $54 \%$ between $23^{\circ} \mathrm{C}$

3 and $11^{\circ} \mathrm{C}$. Such a dependence of MBV upon temperature was expected, since the MBV

$4 \quad\left[\mathrm{~g} /\left(\mathrm{m}^{2} \% \mathrm{RH}\right)\right]$ is calculated from the relative humidity value which depends on temperature.

5 Table 6 reports the calculated value of $\mathrm{MBV}_{\text {ideal }}(\mathrm{Cf}$. Equations 4 and 5 ) and the moisture

6 penetration depth for the DPC material deduced from experimental results of Haba et al. [9],

7 and the same quantities obtained from literature data for some other bio-based materials [11].

8 These values represent referential values calculated by assuming a sinusoidal variation, which

$9 \quad$ must be considered only as an approximation.

Table 5: Moisture buffer values (MBV) at adsorption-desorption phases and average MBV

for the DPC material subjected to MBV conditions at 23 and $10^{\circ} \mathrm{C}$.

\begin{tabular}{lcc}
\hline Temperature & $\mathbf{2 3}^{\circ} \mathbf{C}$ & $\mathbf{1 0}^{\circ} \mathbf{C}$ \\
\hline MBV- adsorption $\left[\mathrm{g} /\left(\mathrm{m}^{2} \% \mathrm{RH}\right)\right]$ & 2.96 & 2.03 \\
MBV- desorption $\left[\mathrm{g} /\left(\mathrm{m}^{2} \% \mathrm{RH}\right)\right]$ & 2.98 & 1.97 \\
MBV- average $\left[\mathrm{g} /\left(\mathrm{m}^{2} \% \mathrm{RH}\right)\right]$ & 2.97 & 2.00
\end{tabular}

Table 6: Hygric properties of some bio-based concretes or mortars.

\begin{tabular}{ccccc}
\hline $\begin{array}{c}\mathbf{D}_{\mathbf{w}} \\
{\left[\mathbf{m}^{2} / \mathbf{s}\right]}\end{array}$ & $\begin{array}{c}\mathbf{b}_{\mathbf{m}} \\
{\left[\mathbf{k g} /\left(\mathbf{m}^{\mathbf{2}} \mathbf{P a ~ s}{ }^{\mathbf{1} / \mathbf{2}}\right)\right]}\end{array}$ & $\begin{array}{c}\text { MBVideal } \\
{\left[\mathbf{g} /\left(\mathbf{m}^{\mathbf{2} \% \mathbf{R H})]}\right.\right.}\end{array}$ & $\begin{array}{c}\mathbf{d P . 1 \%} \\
{[\mathbf{c m}]}\end{array}$ & Ref \\
\hline $2.20 \times 10^{-9}$ & $8.07 \times 10^{-7}$ & 3.79 & 3.50 & $\begin{array}{c}\text { This work } \\
\text { and [9] }\end{array}$
\end{tabular}

\begin{tabular}{llllll}
$\begin{array}{l}\text { Hemp lime } \\
\text { concrete }\end{array}$ & $1.54 \times 10^{-9}$ & $5.67 \times 10^{-7}$ & 2.66 & 3.01 & {$[11]$} \\
$\begin{array}{l}\text { Flax lime } \\
\text { concrete }\end{array}$ & $1.44 \times 10^{-9}$ & $6.16 \times 10^{-7}$ & 2.89 & 2.91 & {$[11]$} \\
\hline
\end{tabular}


1 The experimental variations of the relative humidity at the surface and at a depth of $35 \mathrm{~mm}$ are

2 represented in Figure 11 for the DPC material, both at temperatures of $10^{\circ} \mathrm{C}$ and $23^{\circ} \mathrm{C}$.

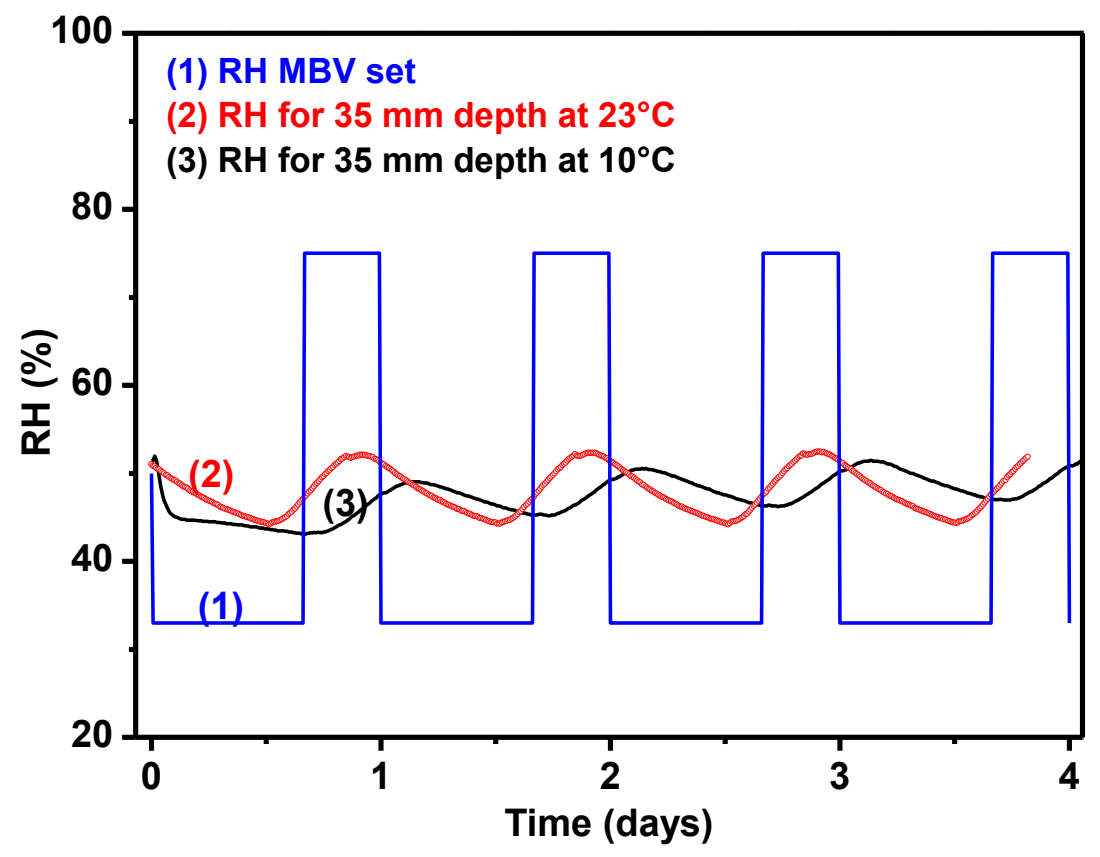

Figure 11: Relative humidity and temperature measured at the surface and at the middle of the DPC sample during MBV tests at $23^{\circ} \mathrm{C}$ and $10^{\circ} \mathrm{C}$.

It seems that at the depth of $35 \mathrm{~mm}$, the sample is only little affected by the cyclic RH variation

taking place in the climatic chamber. This experimental result is consistent with the penetration depth around $35 \mathrm{~mm}$ which was calculated in Table 6 using the Nordtest protocol.

This feature is of major interest with regard to the regulation of external variation of humidity, and appears as a main advantage of DPC mortar over other bio-based materials.

Results obtained in the present work motivate further development of this new DPC material for building applications. In particular, transfer properties at the structural scale (on wall panels) should be explored in future studies. 


\section{Conclusions}

2 This paper explores both the effect of temperature and the hysteresis phenomenon on the

3 sorption-desorption process in innovative date palm fiber-reinforced cement (DPC) composite.

4 In a first stage, an investigation was performed under static condition to characterize the

5 sorption-desorption isotherm behavior and the hysteretic effect. It was found that: (i) the DPC 6 material exhibits a high hygric capacity, (ii) the sorption isotherm curve can be satisfactorily 7 fitted using the GAB model, (iii) an important hysteresis effect occurs between the sorption8 desorption phases. In a second step, dynamic conditions were used to investigate the capacity 9 of DPC to moderate the effect of external humidity variations. A MBV value of 2.97[g/ $\left.\left(\mathrm{m}^{2} \% \mathrm{RH}\right)\right]$ was measured for DPC mortar, which is classified as an excellent moisture buffer value according to the Nordtest specifications. Furthermore, it was shown that temperature has an important impact on the hygric behavior of DPC mortar. Finally, the moisture penetration depth was estimated at $35 \mathrm{~mm}$; at this depth, DPC samples are only little affected by external variations of relative humidity.

As a conclusion, DPC mortar can be considered as a composite material with excellent hygrothermal properties and is highly recommended for building applications.

\section{Acknowledgements}

This research was conducted with financial support of PHC TASSILI Project 16MDU976. 


\section{References}

[1] A. Kylili, P. A. Fokaides, Policy trends for the sustainability assessment of construction materials: A review, Sustainable Cities and Society, 35 (2017) 280-288.

[2] F. Asdrubali, S. Schiavoni, A review of unconventional sustainable building insulation materials, Sustainable Materials and Technologies, 4 (2015), 1-17.

[3] B. Agoudjil, A. Boudenne, L. Ibos, M. Fois, Renewable materials to reduce building heat loss: Characterization of date palm wood, Energy and Buildings, 43 (2011), 491497.

[4] N. Benmansour, B. Agoudjil A. Gherabli, A. Kareche, A. Boudenne, Thermal and mechanical performance of natural mortar reinforced with date palm fibers for use as insulating materials in building, Energy and Buildings, 81 (2014), 98-104.

[5] M. Chikhi, B. Agoudjil, A. Boudenne, A. Gherabli, Experimental investigation of new biocomposite with low cost for thermal insulation, Energy and Buildings, 66 (2013), 267-273.

[6] M. Haddadi, N. Benmansour, B. Agoudjil, A. Boudenne, B. Garnier, Experimental and modeling study of effective thermal conductivity of polymer filled with date palm fibers, Polymer Composites, 38 (2017) 1712-1719.

[7] M. Boumhaout, L. Boukhattem, H. Hamdi, B. Benhamou, F. Ait Nouh Thermomechanical characterization of a bio-composite building material: Mortar reinforced with date palm fibers mesh, Construction and Building Materials 135 (2017) $241-250$.

[7] L. Boukhattem, M. Boumhaout, , H. Hamdi, B. Benhamou, F. Ait Nouh Moisture content influence on the thermal conductivity of insulating building materials made from date palm fibers mesh, Construction and Building Materials 148 (2017) 811-823.

[9] B. Haba, B. Agoudjil A. Boudenne, K. Benzarti, Hygric properties and thermal conductivity of a new insulation material for building based on date palm concrete, Construction and Building Materials, 154 (2017), 963-971.

[10] J. Toftum, O. Fanger, Application of a Whole-Building Hygrothermal model in energy, durability, and indoor humidity retrofit design, Building Physics, 39(2015)3-34.

[11] M. Rahim, O. Douzane, A.D.T. Le, G. Promis, B. Laidoudi, A. Crigny, B. Dupre, T. Langlet, Characterization of flax lime and hemp lime concretes: Hygricproperties and moisture buffer capacity, Energy and Buildings, 88 (2015) 91-99. 
[12] M. Rahim, O. Douzane, G. Promis, T. Langlet, Numerical investigation of the effect of non-isotherm sorption characteristics on hygrothermal behavior of two bio-based building walls, Journal of Building Engineering, 7 (2016) 263-272.

[13] F. Collet, S. Pretot, C. Lanos, Comparison of the hygric behaviour of three hemp concretes, Energy and Buildings, 62 (2013) 294-303.

[14] A. Bourdot, G. Promis, A.D. T. Le, O. Douzane, A. Benazzouk, F. Rosquoet, T. Langlet, Hygrothermal properties of blocks based on eco aggregates: Experimental and numerical study, Construction and Building Materials, 125 (2016) 279-289.

[15] Y.A. Oumeziane, M. Bart, C. Lanos, Influence of temperature on sorption process in hemp concrete, Construction and Building Materials, 106 (2017) 600-607.

[16] E. Latif, M.A. Ciupala, D.C. Wijeyesekera, D. Newport, Hygric properties of hemp bioinsulations with differing compositions, Construction and Building Materials, 66 (2014) 702-711.

[17] D. Lelievre, T. Colinart, P. Glouannec, Hygrothermal behavior of bio based building materials including hysteresis effects: Experimental and numerical analyses, Energy and Buildings, 84 (2014) 617-627.

[18] C. Rode, Moisture Buffering of BuildingMaterials, Report BYG.DTUR-126 2005, ISSN 1601-2917 ISBN 87-787-195.

[19] Y. Mualem, A Conceptual Model of Hysteresis, Water Resources Research, 10 (1974), 514-520, 1974.

[20] C. Rode, A. K. GRAU, Moisture Buffering of Building Materials, Building Physics, 31 (2008) 333-360.

[21] EN ISO. 12572, Hygrothermal performance of building materials and products Determination of water vapour transmission properties - Cup method, BS EN ISO 125722016.

[22] EN ISO. 12571, Hygrothermal performance of building materials and productsDetermination of hygroscopic sorption properties,BS EN ISO 125712013

[23] M.Th. Van Genuchten, A closed-form equation for predicting the hydraulic conductivity of unsaturated soils, Soil Sci. Soc. Am. J. 44 (1980) 892-898.

[24] E. Barett, L.Joyner, P. Halenda, distributions, The determination of pore volume and area in porous substances. Am. Computations from nitrogen isotherms, J. Chem. Soc. 73 (1951) 373-380.

[25] S. Brunauer, P. Emmet, E.Teller, J.Adsorption of gases in multimolecular layers, Am. Chem. Soc.60 (1938) 309-319. 
1 [26] E. Guggenheim, Application of Press, Statistical Mechanics, (Chapter11), Clarendon Oxford, 1966.

[27] J. B. Condon, Surface Area and Porosity Determinations by Physi-sorption. Measurements and theory, Elsevier Science,2006

[28] C. M. Chen, F. F.Wangaard, Wettability and the hysteresis effect in the sorption of water vapor by wood, Wood Science and Technology, 2 (1968) 177-187.

[29] J. F. Siau, Transport processes in wood. Berlin: Springer-Varlag, 1984.

[30] X. Zhang, W. Zillig, HM. Künzel, C.Mitterer, Combined effects of sorption hysteresis and its temperature dependency on wood materials and building enclosures-part II: Hygrothermal modeling, Building and Environment, 106 (2016), 181-195

[31] H.J. Moon, J.T. Kim, The effect of moisture transportation residential on energy efficiency and IAQ in buildings, Energy and building, 75 (2014), 439-446.

[32] M. Palumbo, A.M. Lacasta, N. Holcrof, A. Shea, P. Walker, Determination of hygrothermal parameters of experimental and commercial bio-based insulation materials, Construction and Building Materials ,124 (2016), 269-275.

[33] C. Feng, H. Janssen, Hygric properties of porous building materials (II): Analysis of temperature influence, Building and Environment, 99 (2016), 107-118.

[34] B. Mazhoud, F. Collet, S. Pretot, J. Chamoin, Hygric and thermal properties of hemp lime plasters, Building and Environment, 96 (2016), 206-216.

[35] S. Poyet, S. Charles, Temperature dependence of the sorption isotherms of cementbased materials: Heat of sorption and Clausius-Clapeyron formula,Cement and Concrete Research, 39 (2009), 1060-1067.

[36] S. Poyet, Experimental investigation of the effect of temperature on the first desorption isotherm of concrete, Cement and Concrete Research, 39 (2009), 1052-1059.

[37] T. Ishida, K. Maekawa, T. Kishi, Enhanced modeling of moisture equilibrium and transport in cementitious materials under arbitrary temperature and relative humidity history, Cement and Concrete Research, 37 (2007), 565-578.

[38] F.Casanova, C.P.Li, I. K. Schuller, Direct observation of cooperative effects in cappillary condensation: The hysteretic origine, Applied Physics letters, 243103(2007), 1-3. 